\title{
Prediction of Compressive Strength of Biodegradable Mg-Zn/HA Composite via Response Surface Methodology and Its Biodegradation
}

\author{
Loy Liang Soon ${ }^{1} \cdot$ Hussain Zuhailawati $^{1} \cdot$ Ismail Suhaina $^{1} \cdot$ Brij Kumar Dhindaw $^{2}$
}

Received: 13 October 2015/Revised: 9 December 2015/Published online: 7 April 2016

(C) The Chinese Society for Metals and Springer-Verlag Berlin Heidelberg 2016

\begin{abstract}
This work aimed to fabricate magnesium zinc/hydroxyapatite $(\mathrm{Mg}-\mathrm{Zn} / \mathrm{HA})$ composite via powder metallurgy method and to develop a mathematical model to predict the compressive strength of the composite using response surface methodology method. The effect of various mechanical milling parameters, milling speed (200-300 r/min), ball-to-powder weight ratio (5-12.5) and HA content (2.6-10 wt\%) on the compressive strength of $\mathrm{Mg}-\mathrm{Zn} / \mathrm{HA}$ composite was investigated. The model shows that high compressive strength of $\mathrm{Mg}-\mathrm{Zn} / \mathrm{HA}$ composite was achieved when the powders were prepared with high milling speed and ball-topowder weight ratio and low HA content. The mathematical model was adequate with error percentage lower than $3.4 \%$. The microstructure of $\mathrm{Mg}-\mathrm{Zn} / \mathrm{HA}$ composite with different process parameters revealed that fine microstructure was observed at high milling speed and ball-to-powder weight ratio while agglomeration of HA was found in composite with 10 wt\% HA. The agglomeration of HA led to degradation of interfacial bonding strength between matrix and reinforcement phases and hence decreased the overall compressive strength of $\mathrm{Mg}-\mathrm{Zn} / \mathrm{HA}$ composite. Biodegradation test revealed that sample with higher $\mathrm{HA}$ content had more weight gain and there was more formation of hydroxyapatite. $\mathrm{Mg}-\mathrm{Zn} / \mathrm{HA}$ composite with $8 \mathrm{wt} \% \mathrm{HA}$ was found to be the best candidate for implant application because it had considerable compressive strength and good biodegradation properties.
\end{abstract}

KEY WORDS: Powder metallurgy; Magnesium-zinc alloy; Hydroxyapatite; Response surface methodology; Biodegradation

\section{Introduction}

Magnesium ( $\mathrm{Mg}$ ) alloys have great potential as a biodegradable metal implant because they can be gradually dissolved in human body; hence, secondary operation for

Available online at http://link.springer.com/journal/40195

Hussain Zuhailawati

zuhaila@usm.my

1 Structural Materials Niche Area Group, School of Materials and Mineral Resources Engineering, Engineering Campus, Universiti Sains Malaysia, 14300 Nibong Tebal, Penang, Malaysia

2 School of Minerals Metallurgical and Materials Engineering, Indian Institute of Technology Bhubaneswar, Bhubaneswar 751007, India implant removal can be avoided [1]. Besides that, magnesium alloy has lower Young's modulus compared to conventional metals for implant which reduces the stress shielding effect. However, many alloying elements are harmful to human body leaving only a few options like, calcium (Ca), manganese (Mn) and zinc (Zn) [1, 2]. Zhang et al. [3] stated that addition of Zn improves the mechanical properties and corrosion properties of $\mathrm{Mg}$. Besides that, $\mathrm{Mg}-\mathrm{Zn}$ alloys are biodegradable, thus adding value to $\mathrm{Mg}-\mathrm{Zn}$ alloys as implant materials. Bioceramics have good corrosion resistance and osteoconductivity, but they are brittle and hence are not used as implant material alone. Therefore, researchers combine the metals and ceramics forming composites which have the qualities from both metals and ceramics. Hydroxyapatite (HA) is by far the most commonly used bioceramics in bone replacement application due to its close resemblance to bone mineral 
[4]. Addition of HA is reported to enhance the corrosion properties and osteoconductivity, but at the same time deteriorate the mechanical properties of metal implant. Therefore, HA is often used as a coating for metal implants instead of in composite form to avoid deterioration of strength of the implants. However, recent studies have proved the possibility of its use in composite form which inspires the idea to add $\mathrm{HA}$ into $\mathrm{Mg}-\mathrm{Zn}$ biodegradable alloy creating a new composite, $\mathrm{Mg}-\mathrm{Zn} / \mathrm{HA}$ composite.

There were many $\mathrm{Mg}-\mathrm{Zn}$-based alloy and other metal based composites reinforced by HA fabricated by powder metallurgy method [2, 4]. Besides that, fabrication of $\mathrm{Mg}-$ $\mathrm{Zn} / \mathrm{HA}$ composite via powder metallurgy had been attempted earlier [5]. However, the fabrication method of $\mathrm{Mg}-\mathrm{Zn} / \mathrm{HA}$ composite is not well established and the suitable processing parameters to fabricate the composite are yet to be discovered. Preparation of powder mixture is the main process in powder metallurgy method because properties of the final product are affected by properties of powders. Preparation of alloy powder mixture can be done by spray atomization method as reported by Zhao et al. [6] or by mechanical milling method $[2,7,8]$. Mechanical milling is a ball milling process where the powder mixture is subjected to high-energy collision from the milling balls [9]. Mechanical milling is often used to prepare alloy powders because alloying mechanism occurs during the milling process. The powders are deformed and cold-welded together because they are subjected to high impact energy during the milling process. When powders with different chemical elements are cold-welded together, alloying mechanism happens. Mechanical strength of the sintered composite depends highly on the properties of powders which are affected by various mechanical milling parameters including milling speed, milling time, milling temperature, ball-to-powder weight ratio (BPR), material of grinding media, size of grinding media, geometry of mill and powder composition. Milling speed, BPR and HA content have significant effect on the final properties of the composite as Salleh et al. [2] reported that milling speed and BPR had great effect on density of $\mathrm{Mg}-\mathrm{Zn}$ alloy while Khalil [10] reported that increase in HA reduces the mechanical properties of $\mathrm{Mg} / \mathrm{HA}$ composite. Therefore, milling speed, BPR and fraction of HA were selected in this study to investigate their effect on the compressive strength of $\mathrm{Mg}-\mathrm{Zn} / \mathrm{HA}$ composite.

In order to investigate the effect of milling parameters on the compressive strength of the $\mathrm{Mg}-\mathrm{Zn} / \mathrm{HA}$ composite, design of experiment (DoE) approach can be used. Conventional trial and error method will use too much cost and time as there are too many factors to be considered. DoE reduced the number of experiment runs, hence reducing the cost and time. Response surface methodology (RSM) is a commonly used DoE method for mathematical modelling and analysis of problems where the response is influenced by multiple variables [11]. RSM is a helpful tool which can help to develop a mathematical model equation for the response and predict the response based on the model. This work is the pioneer in the investigation of the effect of process parameters on mechanical properties of $\mathrm{Mg}-\mathrm{Zn} /$ HA composite. This work proposed a mathematical model for prediction of compressive strength of $\mathrm{Mg}-\mathrm{Zn} / \mathrm{HA}$ composite. In addition, biodegradation properties of $\mathrm{Mg}-$ $\mathrm{Zn} / \mathrm{HA}$ composite were also studied.

\section{Materials and Methods}

\subsection{Materials}

Magnesium (99.00\% pure), zinc $(99.70 \%$ pure) and hydroxyapatite powders were used as raw materials in the experiment. The $\mathrm{Mg}$ and $\mathrm{Zn}$ powders were from MERCK Schuchardt OHG while the HA powders were from SigmaAldrich. The particle size of elemental $\mathrm{Mg}$ powder, $\mathrm{Zn}$ powder and HA powders was up to 227.41, 121.65 and $10.77 \mu \mathrm{m}$, respectively.

\subsection{Matrix Generation}

The effect of input parameters on the fabrication of $\mathrm{Mg}$ $\mathrm{Zn} / \mathrm{HA}$ composite and the prediction for the compression strength of $\mathrm{Mg}-\mathrm{Zn} / \mathrm{HA}$ composite was studied by design of experiment (DoE) approach. The selected DoE was RSM coupled with CCD design and was carried out by Minitab 16 (Minitab Inc, USA).

There are many mechanical alloying factors that have significant influence on the mechanical properties of mechanically alloyed powders [2]. However, this study focused only on milling speed, ball-to-powder weight ratio (BPR) and fraction of HA in order to reduce the complexity of the experiment. According to the literature review, these are the major factors in determining composite properties whose powders were prepared by mechanical milling. The upper limit and lower limit for parameters of interest, milling speed, ball-to-powder weight ratio and amount of HA were set according to values shown in Table 1 based on findings reported by Salleh et al. [2] and Khalil [10]. In the present work, a set of design matrix was also generated using RSM Minitab as shown in Table 2 and the experiment was run following sequence of run order in the matrix.

\subsection{Sample Preparation}

Different amount of HA powders and the balanced Mg and $\mathrm{Zn}$ powders were mixed in weight proportion. The 
Table 1 Process parameters in CCD, coded and uncoded values

\begin{tabular}{llrc}
\hline Level & Milling speed $(\mathrm{r} / \mathrm{min})$ & BPR & HA content $(\mathrm{wt} \%)$ \\
\hline$-\alpha$ & 165.91 & 2.44 & 0.08 \\
-1 & 200.00 & 5.00 & 2.60 \\
0 & 250.00 & 8.75 & 6.30 \\
1 & 300.00 & 12.50 & 10.00 \\
$+\alpha$ & 334.09 & 15.06 & 12.52 \\
\hline
\end{tabular}

Table 2 Experimental design matrix

\begin{tabular}{llll}
\hline Run order & Milling speed & BPR & HA content \\
\hline 1 & + & - & + \\
2 & - & - & + \\
3 & + & - & - \\
4 & 0 & 0 & 0 \\
5 & 0 & $-\alpha$ & 0 \\
6 & - & + & - \\
7 & - & + & + \\
8 & 0 & 0 & $-\alpha$ \\
9 & 0 & $+\alpha$ & 0 \\
10 & 0 & 0 & 0 \\
11 & 0 & 0 & 0 \\
12 & - & - & - \\
13 & 0 & 0 & 0 \\
14 & 0 & 0 & 0 \\
15 & $-\alpha$ & 0 & 0 \\
16 & 0 & 0 & $+\alpha$ \\
17 & + & + & - \\
18 & 0 & 0 & 0 \\
19 & + & + & + \\
20 & $+\alpha$ & 0 & 0 \\
\hline & & &
\end{tabular}

balanced $\mathrm{Mg}$ and $\mathrm{Zn}$ powders were fixed at a ratio of $\mathrm{Mg}$ to $\mathrm{Zn}$ of 94:6. $\mathrm{Mg}, \mathrm{Zn}$, and HA powders were mixed and milled by Fritsch Pulveristte P-5 planetary mill machine according to the required milling speed, BPR and HA content. Interval of $30 \mathrm{~min}$ rest after $30 \mathrm{~min}$ of milling was set to control the temperature increment of the grinding jar. The milled powders were then pressed into pellets with $400 \mathrm{MPa}$ using hand press machine. The pressed samples were sintered in a Lenton tube furnace at $350{ }^{\circ} \mathrm{C}$ in the presence of argon gas for $3 \mathrm{~h}$. Both heating and cooling rates used were $10{ }^{\circ} \mathrm{C} / \mathrm{min}$.

\subsection{Statistical Analysis and Verification Test}

The compression test was done by the universal testing machine INSTRON 5982 using ASTM E9-89a standard as a reference. The samples with size of $13 \mathrm{~mm}$ diameter and $13 \mathrm{~mm}$ height were subjected to $100 \mathrm{kN}$ load with the loading rate of $1.00 \mathrm{~mm} / \mathrm{min}$. The compressive strengths of three replicates were determined, and the average for each run was calculated. The average value of compressive strength was used as the response for RSM analysis.

The compressive strength results obtained were all tabulated. Regression analysis was performed using Minitab software to analyse the response data and develop a model equation for compressive strength. Contour plots were also plotted based on the model equation to study the effect of interactions of factors on the response. Based on the contour plots, verification tests were carried out to compare the actual experimental result with the predicted result.

\subsection{Characterization}

The actual densities of each run were measured by pycnometer density equipment using Archimedes' principle. The samples were first placed on a Sartorius electronic analytical balance before being immersed in water which was also placed on the Sartorius electronic analytical balance with four decimals accuracy. Three readings were taken for each run, and the average density was reported. The relative density $\left(\rho_{\mathrm{r}}\right)$ was calculated by

$\rho_{\mathrm{r}}=\rho_{\mathrm{ac}} / \rho_{\mathrm{th}} \times 100 \%$,

$\rho_{\text {th }}=\rho_{\mathrm{Mg}} V_{\mathrm{Mg}}+\rho_{\mathrm{Zn}} V_{\mathrm{Zn}}+\rho_{\mathrm{HA}} V_{\mathrm{HA}}$,

$V_{\mathrm{Mg}}+V_{\mathrm{Zn}}+V_{\mathrm{HA}}=1$,

where $\rho_{\mathrm{r}}, \rho_{\mathrm{ac}}$ and $\rho_{\mathrm{th}}$ represent the relative density, actual density and theoretical density of the samples, respectively; $\rho_{\mathrm{Mg}}=1.74 \mathrm{~g} / \mathrm{cm}^{3}, \quad \rho_{\mathrm{Zn}}=7.14 \mathrm{~g} / \mathrm{cm}^{3}$ and $\rho_{\mathrm{HA}}=3.16$ $\mathrm{g} / \mathrm{cm}^{3}$ represent the density of $\mathrm{Mg}, \mathrm{Zn}$ and HA, respectively; $V_{\mathrm{Mg}}, V_{\mathrm{Zn}}$ and $V_{\mathrm{HA}}$ represent the volume fraction of $\mathrm{Mg}, \mathrm{Zn}$ and $\mathrm{HA}$, respectively.

Selected sintered samples were subjected to qualitative X-Ray diffraction (XRD) test. The test was done by D8 Advance, Bruker AXS, with angular scanning range of $20^{\circ} \leq 2 \theta \leq 90^{\circ}$. Phase identification was carried out from diffractogram of $K_{\alpha 2}$ component intensity versus $2 \theta$. The peaks of the samples were analysed using X'Pert Highscore software. The crystallite size was also estimated using the software.

The crystallite size was calculated by Scherrer equation as:

$D=\frac{0.9 \lambda}{\beta \cos \theta}$,

where $D$ is the average crystalline size, $\lambda$ is the wavelength of X-ray, $\theta$ is the Bragg's angle and $\beta$ is the full width at half maximum. 
Internal strain was also determined by the WilliamsonHall method as:

$B_{\mathrm{r}} \cos \theta=\frac{0.89}{D} \lambda+2 \eta \sin \theta$

where $B_{\mathrm{r}}$ is the line broadening and $\eta$ is the internal strain.

The microstructure of sintered selected samples was studied with optical microscope MEIJI and field emission scanning electron microscope (FESEM) ZEISS ZUPRA 35VP. EDX analysis was also carried out.

\subsection{Immersion Test}

Samples with different fractions of HA were prepared using milling speed of $270 \mathrm{r} / \mathrm{min}$ and BPR of 8.75 . The selected processing parameters were based on the contour plots. The samples were immersed in SBF (Hank's solution) maintained at $37^{\circ} \mathrm{C}$ in water bath for $5 \mathrm{~h}$. After $5 \mathrm{~h}$ immersion, the samples were taken out and rinsed with distilled water to remove the residue. The samples were then dried in oven at $100{ }^{\circ} \mathrm{C}$ for $1 \mathrm{~h}$. The initial weight and final weight of the samples were measured by electronic balance, and the weight gain was calculated.

\section{Results and Discussion}

\subsection{Statistical Analysis of Results}

The responses (compressive strength) of all the experimental runs are listed in Table 3. The average value of the compressive strength for three replicates was recorded as the final response. The experimental results obtained were analysed by regression analysis. Table 4 shows the results of regression analysis with a confidence level of $95 \%$.

According to the results in Table 4, the $p$ value for linear variables was $<0.05$, indicating that the linear factors were significant. A $p$ value which is lower than 0.05 explaining the variable is significant while a $p$ value higher than 0.05 is otherwise. It was observed that $p$ value of the fraction of HA was statistically significant. Effect of milling speed can also be considered as significant with a reasonable confidence level of $94 \%$ as indicated by the $p$ value for this factor. However, $p$ value for BPR has significance at a confidence level of little $<50 \%$. In the analysis of the results, the effect of BPR has also been included in the regression equation. The implication of including BPR effect in the regression equation would be analysed later to understand the role of this important factor in the properties of the sintered composites. The square factor milling speed had a $p$ value of 0.073 which was higher than 0.05 . Although its $p$ value was higher, it was also being considered as its $p$ value was near to 0.05 .

\subsection{Development of Regression Model Equation}

As per statistical analysis presented in Sect. 3.1, the following model equation which correlates the compressive strength to various factors is obtained:

$$
\begin{aligned}
y= & -242.972+3.345 x_{1}+1.237 x_{2}-5.206 x_{3} \\
& -0.006 x_{1}^{2},
\end{aligned}
$$

where $y$ is the compressive strength, $x_{1}$ is the factor for milling speed, $x_{2}$ is the factor for BPR, $x_{3}$ is the factor for HA content and $x_{1}^{2}$ is the quadratic function for milling speed.

According to the model equation, milling speed, BPR, HA content and quadratic function for milling speed have the coefficients of $3.345,1.237,-5.206$ and -0.006 , respectively. The effect of the factors on the response is determined by the magnitude of their coefficient. Factors with greater effect to the response in descending order were HA content, milling speed, BPR and quadratic function for milling speed. The negative sign for coefficients of HA content and quadratic function for milling speed indicates a negative effect to the compressive strength. In other words, the compressive strength decreases when HA content increases. Milling speed and BPR factors both have positive effect to the compressive strength. The compressive strength increases as the milling speed and BPR increase.

\subsection{Effect of Factors on Response}

Four samples from the RSM design matrix were selected as shown in Table 5, to study the effect of milling parameters on compressive strength of $\mathrm{Mg}-\mathrm{Zn} / \mathrm{HA}$ composite. Samples 1 and 2 were selected to compare the effect of milling speed on their compressive strength and microstructure. Sample milled with $300 \mathrm{r} / \mathrm{min}$ had a compressive strength of $199 \mathrm{MPa}$ while sample milled with $200 \mathrm{r} / \mathrm{min}$ had a compressive strength of $153 \mathrm{MPa}$. The correlation between compressive strength and milling speed is supported by the model which predicts that the sample with a higher milling speed will have higher strength. When the powder is milled with higher $\mathrm{r} / \mathrm{min}$, the powders are subjected to higher impact energy as more collision with milling balls takes place. When the powders are subjected to higher impact, greater amount of deformation takes place and strain hardening occurs. The strain level and crystallite size obtained from XRD supported this statement. The XRD revealed that the sample milled with $300 \mathrm{r} / \mathrm{min}$ had a higher strain level of 0.058 compared to the sample milled with $200 \mathrm{r} / \mathrm{min}$ (0.051). A high strain level resulted in higher strength due to strain strengthening mechanism. When the structure is strained, the dislocations propagate and eventually meet each other, preventing each other from further propagation. Besides that, sample milled 
Table 3 Compressive strength results

\begin{tabular}{|c|c|c|c|c|}
\hline Run order & Milling speed & BPR & HA content & Compressive strength (MPa) \\
\hline 1 & + & - & + & 198.716 \\
\hline 2 & - & - & + & 153.084 \\
\hline 3 & + & - & - & 244.158 \\
\hline 4 & 0 & 0 & 0 & 230.082 \\
\hline 5 & 0 & $-\alpha$ & 0 & 168.129 \\
\hline 6 & - & + & - & 173.729 \\
\hline 7 & - & + & + & 176.450 \\
\hline 8 & 0 & 0 & $-\alpha$ & 238.113 \\
\hline 9 & 0 & $+\alpha$ & 0 & 239.261 \\
\hline 10 & 0 & 0 & 0 & 191.772 \\
\hline 11 & 0 & 0 & 0 & 202.466 \\
\hline 12 & - & - & - & 163.020 \\
\hline 13 & 0 & 0 & 0 & 216.244 \\
\hline 14 & 0 & 0 & 0 & 175.916 \\
\hline 15 & $-\alpha$ & 0 & 0 & 118.231 \\
\hline 16 & 0 & 0 & $+\alpha$ & 115.712 \\
\hline 17 & + & + & - & 178.532 \\
\hline 18 & 0 & 0 & 0 & 146.731 \\
\hline 19 & + & + & + & 173.963 \\
\hline 20 & $+\alpha$ & 0 & 0 & 175.035 \\
\hline
\end{tabular}

Table 4 Regression analysis results for the mathematical model and coefficient of model terms for the formulation of Mg-Zn/HA composites

\begin{tabular}{|c|c|c|c|c|c|}
\hline Source & Sum of squares & DF & Mean square & $F$ value & $p$ value \\
\hline Regression & $12,392.6$ & 4 & 3098.2 & 3.45 & 0.034 \\
\hline Linear & 9055.9 & 3 & 3018.6 & 3.37 & 0.047 \\
\hline Milling speed & 3694.4 & 1 & 3694.4 & 4.12 & 0.061 \\
\hline BPR & 293.6 & 1 & 293.6 & 0.33 & 0.576 \\
\hline HA content & 5067.9 & 1 & 5067.9 & 5.65 & 0.031 \\
\hline Square of milling speed & 3336.7 & 1 & 3336.7 & 3.72 & 0.073 \\
\hline Lack of fit & 9019.5 & 10 & 901.9 & 1.02 & 0.527 \\
\hline
\end{tabular}

$R^{2}=47.95 \%$; adjusted $R^{2}=34.07 \%$; press is 22,936

Table 5 Parameters, relative density, strain level, crystallite size and compressive strength for selected samples

\begin{tabular}{llrlllll}
\hline Run order & $\begin{array}{l}\text { Milling speed } \\
(\mathrm{r} / \mathrm{min})\end{array}$ & BPR & $\begin{array}{l}\text { HA content } \\
(\mathrm{wt} \%)\end{array}$ & $\begin{array}{l}\text { Relative density } \\
(\%)\end{array}$ & Strain level & $\begin{array}{l}\text { Crystallite size } \\
(\AA)\end{array}$ & $\begin{array}{l}\text { Compressive strength } \\
(\mathrm{MPa})\end{array}$ \\
\hline 1 & 300.00 & 5.00 & 10.00 & 93.07 & 0.058 & 564.5 & 199 \\
2 & 200.00 & 5.00 & 10.00 & 94.42 & 0.051 & 635.5 & 153 \\
3 & 300.00 & 5.00 & 2.60 & 95.12 & 0.041 & 801.0 & 244 \\
17 & 300.00 & 12.50 & 2.60 & 93.58 & 0.066 & 495.4 & 179 \\
\hline
\end{tabular}

with $300 \mathrm{r} / \mathrm{min}$ had smaller crystallite size (564.5 $\mathrm{A}$ ) compared to sample milled with $200 \mathrm{r} / \mathrm{min}(635.5 \AA)$ which resulted in grain boundary strengthening. A material with smaller crystallite size had more grain boundaries which impede dislocation propagation. Therefore, the strength of the material increased. 

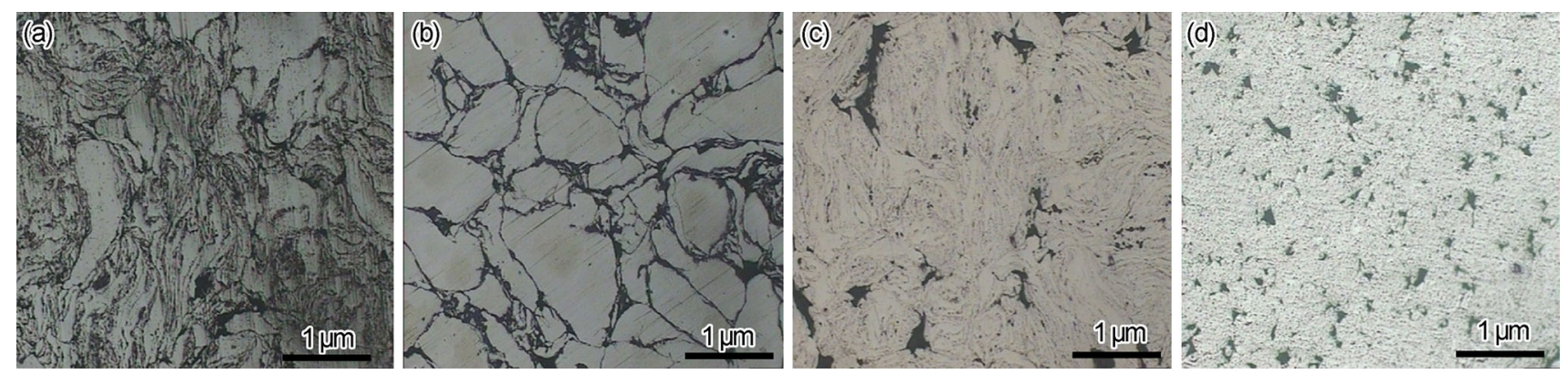

Fig. 1 Optical micrographs of the samples: a sample 1 (300 r/min, BPR 5, $10 \mathrm{wt} \% \mathrm{HA})$; b sample 2 (200 r/min, BPR 5, $10 \mathrm{wt} \%$ HA); c sample 3 (300 r/min, BPR 5, $2.6 \mathrm{wt} \%$ HA); d sample 17 (300 r/min, BPR 12.5, $2.6 \mathrm{wt} \% \mathrm{HA})$
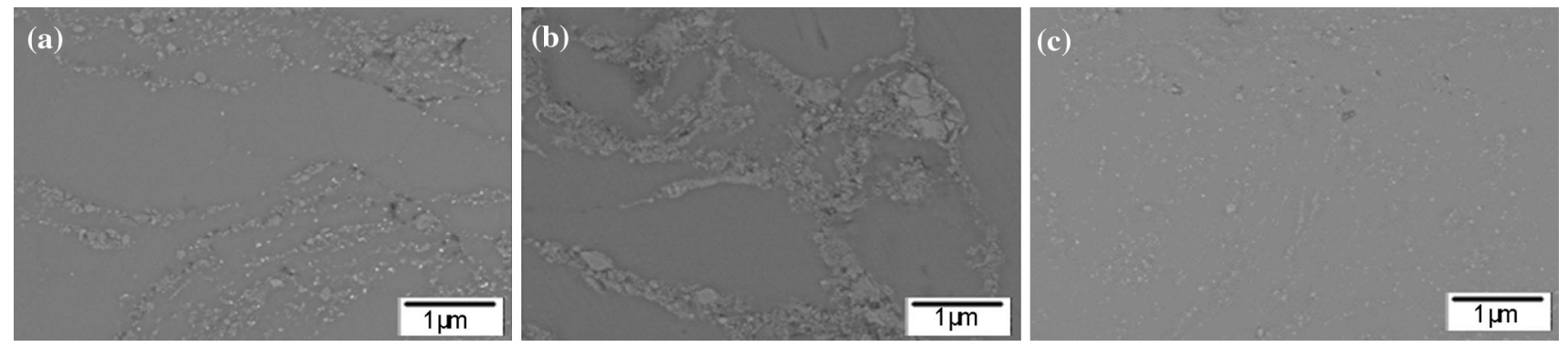

Fig. 2 SEM images of sample 1 a, sample $2 \mathbf{b}$ and sample $3 \mathbf{c}$

The microstructure of the samples observed under optical microscope shown in Fig. 1 also shows that sample milled with $300 \mathrm{r} / \mathrm{min}$ had finer microstructure than sample milled with $200 \mathrm{r} / \mathrm{min}$, indicating that it experienced more collision which resulted in high strain induced in its powders. This finding agrees with the study of Shehata et al. [12], in which it was found that faster milling speed transfers higher kinetic energy into the powders leading to the presence of refined microstructure. Finer grains improve the mechanical properties of the sample; hence, sample with a higher milling speed has better compressive strength. However, the relative density of sample milled with $300 \mathrm{r} / \mathrm{min}$ was lower, indicating that it was supposed to have lower compressive strength because a denser structure has a higher strength. The low relative density is probably due to the higher level of strain experienced by the powders milled with high speed of $300 \mathrm{r} / \mathrm{min}$ which affects the powder compaction. Highly strained powders are difficult to be compacted into a dense structure. In this work, it was observed that even though sample milled with $300 \mathrm{r} / \mathrm{min}$ had a lower relative density than sample milled with $200 \mathrm{r} / \mathrm{min}$, it had a higher compressive strength that is due to high strain level, small crystallite size and its fine microstructure. The effect of density on the compressive strength was not as great as the effect of other factors due to the small difference in relative density.

Besides that, according to Fig. 2, sample milled with higher milling speed $(300 \mathrm{r} / \mathrm{min})$ has a more serious agglomeration of HA particles compared to sample milled with lower milling speed ( $200 \mathrm{r} / \mathrm{min})$. According to Khalil [10], agglomeration of HA particles leads to degradation of interfacial bonding strength between matrix and reinforcement, thus leading to a lower compressive strength. As shown in Fig. 2a, b, the secondary phases agglomerated and took the shape of a spider web in both samples, but the agglomeration is much serious in sample milled with 200 $\mathrm{r} / \mathrm{min}$. EDX analysis verified the secondary white phase as $\mathrm{HA}$ and the dark phase as $\mathrm{Mg}-\mathrm{Zn}$ alloy matrix, as shown in Fig. 3.

Samples 1 and 3 were selected to compare the effects of HA content on the compressive strength and microstructure. Sample 1 with higher HA content $(10 \mathrm{wt} \%)$ had a compressive strength of $199 \mathrm{MPa}$ while sample 3 with lower HA content ( $2.6 \mathrm{wt} \%$ ) had a compressive strength of $244 \mathrm{MPa}$. This finding was supported by the model prediction which indicated that the compressive strength of the $\mathrm{Mg}-\mathrm{Zn} / \mathrm{HA}$ composite decreases with increasing of HA content. The result and the prediction from the model agreed with Khalil [10] finding who found that addition of $10 \mathrm{wt} \% \mathrm{HA}$ and above gives a significant drop in compressive strength and hardness due to agglomeration of HA particles which lead to the degradation of interfacial bonding strength between matrix and reinforcement. As shown in Fig. 2, the secondary phases agglomerated and took the shape of a spider web in the sample with $10 \mathrm{wt} \%$ HA. Meanwhile, the secondary phases were uniformly 


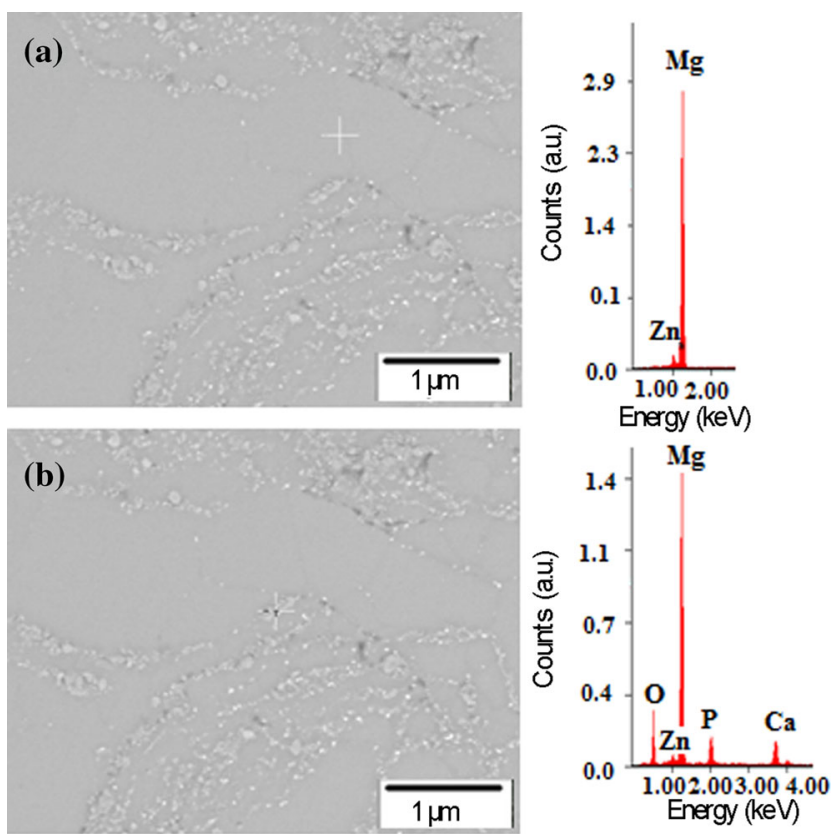

Fig. 3 SEM images and EDX plots at two different spots of sample 1 for primary phase $\mathbf{a}$ and secondary phase $\mathbf{b}$

dispersed within the dark matrix for sample with $2.6 \mathrm{wt} \%$ HA. Figure 3 shows that the secondary white phase is HA while the dark phase is $\mathrm{Mg}-\mathrm{Zn}$ alloy matrix. The agglomeration of HA particles in sample with $10 \mathrm{wt} \% \mathrm{HA}$ could lead to degradation of interfacial bonding strength between matrix and reinforcement as proposed by Khalil [10] and thus had a lower compressive strength.

Besides that, a higher HA content in $\mathrm{Mg}-\mathrm{Zn} / \mathrm{HA}$ powders favours the formation of larger composite particles due to adhesion of $\mathrm{HA}$ particles on $\mathrm{Mg}-\mathrm{Zn}$ alloy [6]. Therefore, $\mathrm{Mg}-\mathrm{Zn} / \mathrm{HA}$ composite with higher HA content had larger particles size which resulted in a lower relative density (93.07\%) compared to that of composite with lower HA content $(95.12 \%)$. These findings agreed with the model prediction which indicated that the compressive strength of the $\mathrm{Mg}-\mathrm{Zn} / \mathrm{HA}$ composite decreases with increasing of HA content.

Samples 3 and 17 were selected to compare the effect of BPR on their compressive strength and microstructure. Sample 3 with BPR of 5 had higher compressive strength of $244 \mathrm{MPa}$ than that of sample 17 with BPR of 12.5 (179 MPa). The model predicted that sample with lower BPR has lower compressive strength than sample with higher BPR. The prediction contradicted with the result. However, it was pointed out in Sect. 3.1 that the confidence level for BPR factor is little $<50 \%$. Thus, this result is not surprising. It only points out to the complex behaviour of the effect of BPR variation on the compressive strength of the sintered composites. The contradiction might be due to occurrence of cold welding mechanism, a solid-state joining process of powders during mechanical milling which varies with the frequency of collision between powders and milling balls that was resulted from different BPR. During the milling process of sample with BPR of 12.5, extensive cold welding occurred and caused the powders cold-welded to the wall of the grinding jar. There were some other samples which experience similar observation, and generally, samples that used high milling speed and BPR were prone to experience cold welding phenomenon. Cold welding might be caused by the relationship between volume of jar, milling balls and powders [9]. According to Fig. 1, sample with BPR of 12.5 had very fine grains, but at the same time it also had many pores. This abundant porosity was the reason for the poorer compressive strength in sample with BPR of 12.5 compared to sample with BPR of 5 . This was supported by relative density of sample with BPR of 12.5 (93.58\%) which was lower than that of sample with BPR of 5 (95.12\%). Thus, the presence of high strains and consequent lattice defects in the high BPR composites coalesces on sintering and forms large number of pores. Therefore, even with the finer grain size in the high BPR sample the strength level obtained is lower compared to that for low BPR.

\subsection{Interaction of Parameters and Model Verification}

Figure 4 shows the contour plot for interaction between HA content and milling speed. The compressive strength decreased rapidly as the HA content increased. This indicated that HA content had a great effect on the compressive strength of $\mathrm{Mg}-\mathrm{Zn} / \mathrm{HA}$ composite. Meanwhile, the relationship between milling speed and the compressive strength was a quadratic function where the optimum strength could be obtained when the speed was roughly between 240 and $320 \mathrm{r} / \mathrm{min}$. Figure 5 shows the contour plot for interaction between BPR and milling speed. This contour plot showed that the highest strength was obtained when the BPR was higher than 10 and milling speed was in the range of $240-310 \mathrm{r} / \mathrm{min}$. Figure 6 shows the contour plot for interaction between HA content and BPR. The greatest response was obtained with lowest HA content and highest BPR. It was also clearly shown that HA content had a greater effect on the compressive strength compared to BPR because the response decreased rapidly with slight increase in HA content. Meanwhile, the response did not increased as much with large increase in BPR.

Based on the contour plots for interaction between HA content and milling speed (Fig. 4), two points were selected for verification test of the model. This contour plot was selected for verification test instead of the other contour plots because HA content and milling speed had greater effect on the compressive strength compared to BPR. The selected 


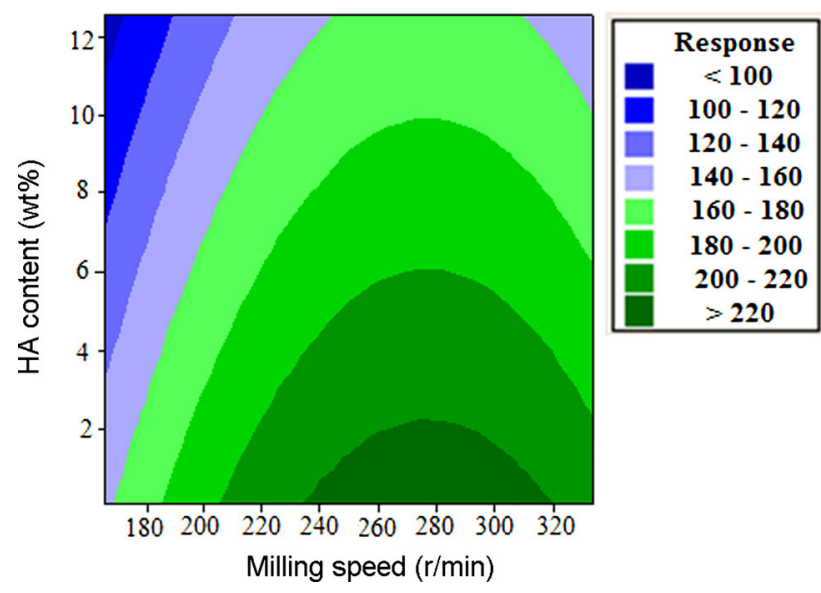

Fig. 4 Contour plot for interaction between HA content and milling speed

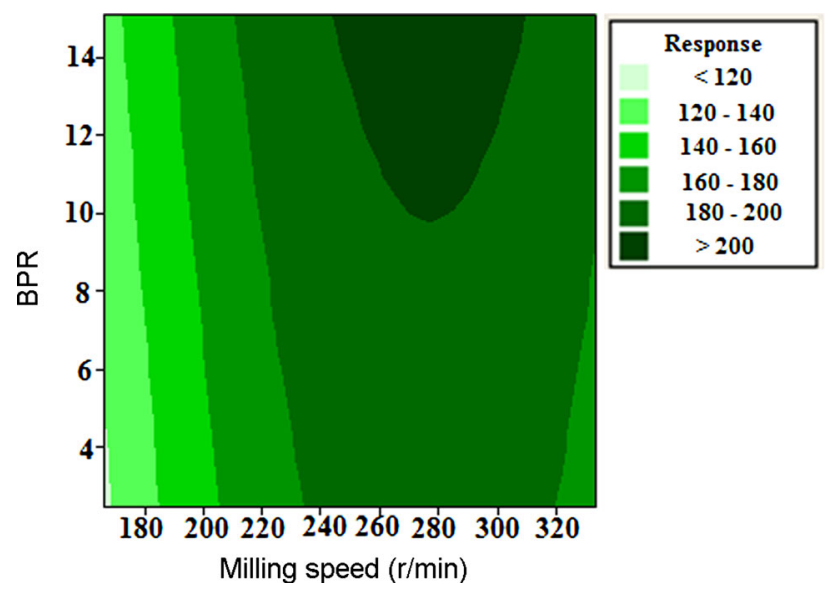

Fig. 5 Contour plot for interaction between BPR and milling speed

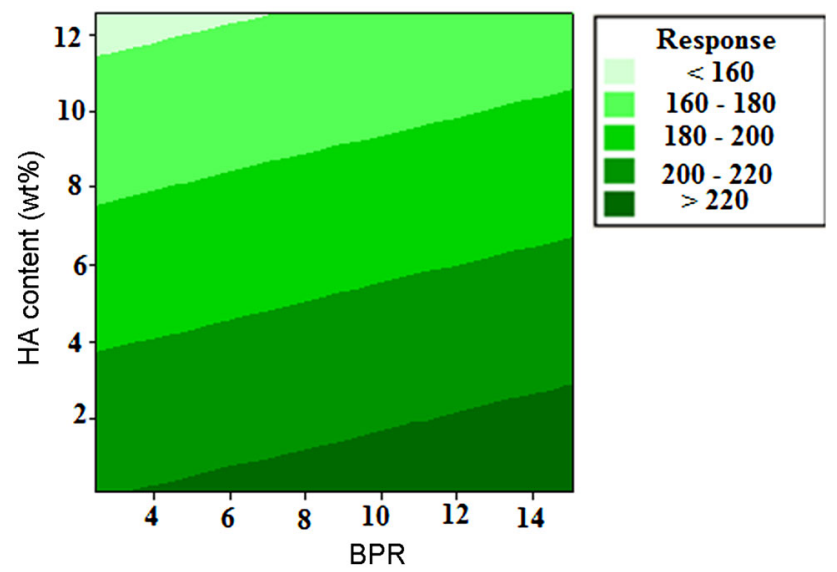

Fig. 6 Contour plot for interaction between HA content and BPR

points were V1 with 5 wt $\%$ HA and V2 with 8 wt $\%$ HA. These two points were selected because their compressive strength was in the range of reported compressive strength
(164-193 MPa) of tibia, femur and humerus bones [13]. For both $\mathrm{V} 1$ and $\mathrm{V} 2$ points, the milling speed is fixed to be $270 \mathrm{r} /$ min because it is the optimum speed while BPR is fixed to be 8.75 because it is the holding value for the contour plot for interaction between HA content and milling speed. The predicted response for the two verification tests was calculated using the model equation [Eq. (6)]. The accuracy of the equation was evaluated by calculating the error percentage between predicted and actual response value. The parameters of the two samples, predicted and actual compressive strengths of the two samples for verification test are listed in Table 6. The actual experimental results for both tests were lower than the predicted values, but they were very close to the predicted values. The error for sample with $5 \mathrm{wt} \% \mathrm{HA}$ and $8 \mathrm{wt} \% \mathrm{HA}$ was 3.38 and $3.23 \%$, respectively. The error was low, and this result confirmed the predictability of the model for the compressive strength of $\mathrm{Mg}-\mathrm{Zn} / \mathrm{HA}$ composite.

\subsection{XRD Analysis}

Figure 7a shows the XRD pattern of $\mathrm{Mg}-\mathrm{Zn} / \mathrm{HA}$ composites with 2.6, 10 and $30 \mathrm{wt} \%$ of HA. According to Fig. 7a, low peaks of HA were found in the samples with 10 and $30 \mathrm{wt} \% \mathrm{HA}$, while sharp $\alpha$-Mg solid solution peaks were observed in all the samples. HA peaks could be detected, but they were broad and their intensities were low; therefore, they were hard to detect. The broad peaks indicated the formation of amorphous HA. The intensity was logarithmic scaled to increase the visibility of the HA peaks, as shown in Fig. 7b. According to Fig. 7b, HA peaks can be observed in all samples. HA peaks were found in the sample with $2.6 \mathrm{wt} \%$ HA despite its low HA content which was claimed to be undetectable by Khalil [10]. In Ref. [10] study, HA peaks were not detected in the $\mathrm{Mg} / \mathrm{HA}$ composite samples with 1-5 wt $\%$ HA due to the low HA content.

\subsection{Biodegradation Properties}

Figure 8 shows the results of immersion test. Sample without HA had a weight loss while the other samples had weight gain. An increasing trend of weight gain with HA content was observed. The increment of weight gain from 5 to $8 \mathrm{wt} \% \mathrm{HA}$ was distinct. The weight gain was due to deposition of apatite on the composite. The corrosion resistance of the composite improved as the corrosion product deposited on the composite. The deposition layer acted as a protective layer preventing further attack of magnesium by SBF [3]. The increasing trend of the weight gain percentage agreed with the results in Ref. [4], in which it was reported that the corrosion resistance of the sample increased with HA content. However, the increment of 
Table 6 Results of verification tests

\begin{tabular}{llllll}
\hline Test & $\begin{array}{l}\text { Milling speed } \\
(\mathrm{r} / \mathrm{min})\end{array}$ & BPR & $\begin{array}{l}\text { HA content } \\
(\mathrm{wt} \%)\end{array}$ & $\begin{array}{l}\text { Predicted compressive } \\
\text { strength (MPa) }\end{array}$ & $\begin{array}{l}\text { Actual compressive } \\
\text { strength (MPa) }\end{array}$ \\
\hline V1 & 270 & 8.75 & 5 & 207.572 & $\begin{array}{l}\text { Error } \\
(\%)\end{array}$ \\
V2 & 270 & 8.75 & 8 & 191.954 & 200.562 \\
\hline
\end{tabular}
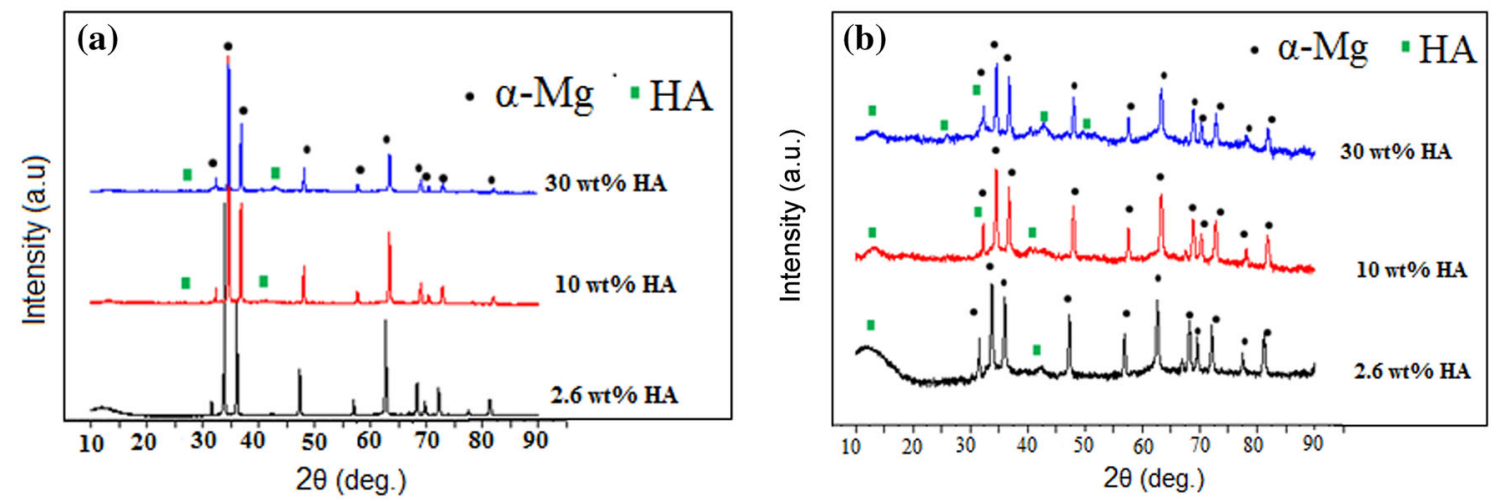

Fig. 7 XRD patterns for $\mathrm{Mg}-\mathrm{Zn} / \mathrm{HA}$ composites with 2.6, 10 and $30 \mathrm{wt} \% \mathrm{HA}$ : a normal pattern; b logarithmic scaled the pattern to increase the visibility of the HA peaks

weight gain percentage as the HA content exceeded $8 \mathrm{wt} \%$ was small, indicating the limit of weight gain caused by deposition layer on $\mathrm{Mg}-\mathrm{Zn} / \mathrm{HA}$ composite.

Figure 9 shows the microstructure of the samples under SEM. As shown in Fig. 9, all the samples experienced pitting corrosion. Cracks were observed in all samples, but sample without and with $1 \mathrm{wt} \%$ HA had more cracks than the other samples. Meanwhile, pitting holes were observed in samples with 5, 8 and 11 wt\% HA. Figure 10 shows the EDX analysis of passivation layer on the sample. The EDX result for the controlled sample without $\mathrm{HA}$ revealed that the surface corrosion products were rich in $\mathrm{Mg}$ and oxygen (O) indicating formation of $\mathrm{Mg}(\mathrm{OH})_{2}$ layer on the surface. According to Liu et al. [5], the cracks were formed due to

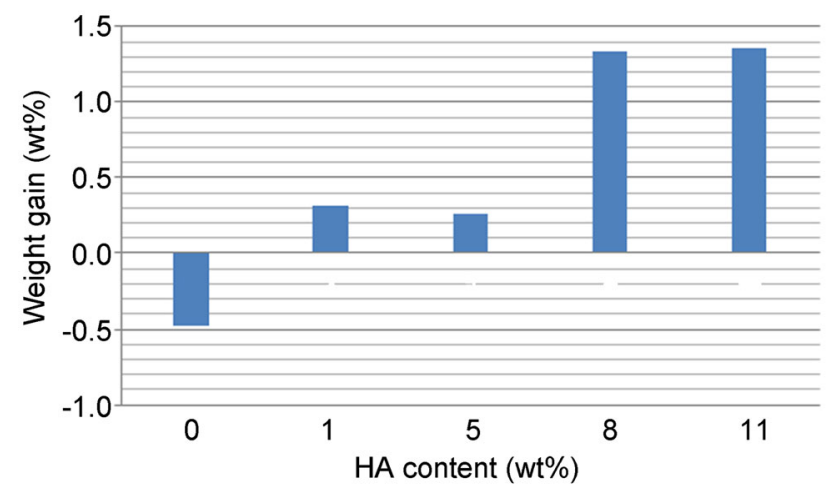

Fig. 8 Weight gain of the $\mathrm{Mg}-\mathrm{Zn} / \mathrm{HA}$ composites with different HA contents dehydration of $\mathrm{Mg}(\mathrm{OH})_{2}$ layer on the surface. Dehydration of $\mathrm{Mg}(\mathrm{OH})_{2}$ to $\mathrm{MgO}$ leads to a shrinkage of interatomic distance from 3.12 to $2.99 \AA$ and hence produces cracks $[14,15]$. Meanwhile, EDX result for the other samples with HA content revealed that there are some calcium $(\mathrm{Ca})$ and phosphorus $(\mathrm{P})$, indicating that hydroxyapatite (HA) layer was deposited on the surface as reported by Liu et al. [5] and Zhang et al. [1]. Liu et al. [5] also reported that the deposited HA protective layer would efficiently prevent pitting and hence decrease the corrosion of $\mathrm{Mg}-\mathrm{Zn} / \mathrm{HA}$ composite. This statement was supported by the SEM images (Fig. 9) which revealed that less cracks and pitting holes were found on the surface as the HA content increases. The results from investigation on compressive strength and biodegradable properties of $\mathrm{Mg}-\mathrm{Zn} / \mathrm{HA}$ composite suggested that addition of $8 \mathrm{wt} \% \mathrm{HA}$ is the best. This is because the sample with $8 \mathrm{wt} \% \mathrm{HA}$ had compressive strength within the range of that of bone (164-193 MPa) and had high weight gain indicating abundant formation of apatite layer which helps to improve corrosion resistance and osteoconductivity.

\section{Conclusions}

The effect of processing parameters on the compressive strength of $\mathrm{Mg}-\mathrm{Zn} / \mathrm{HA}$ composite fabricated by powder metallurgy method using RSM approach revealed that the compressive strength of the composite decreased as the HA 

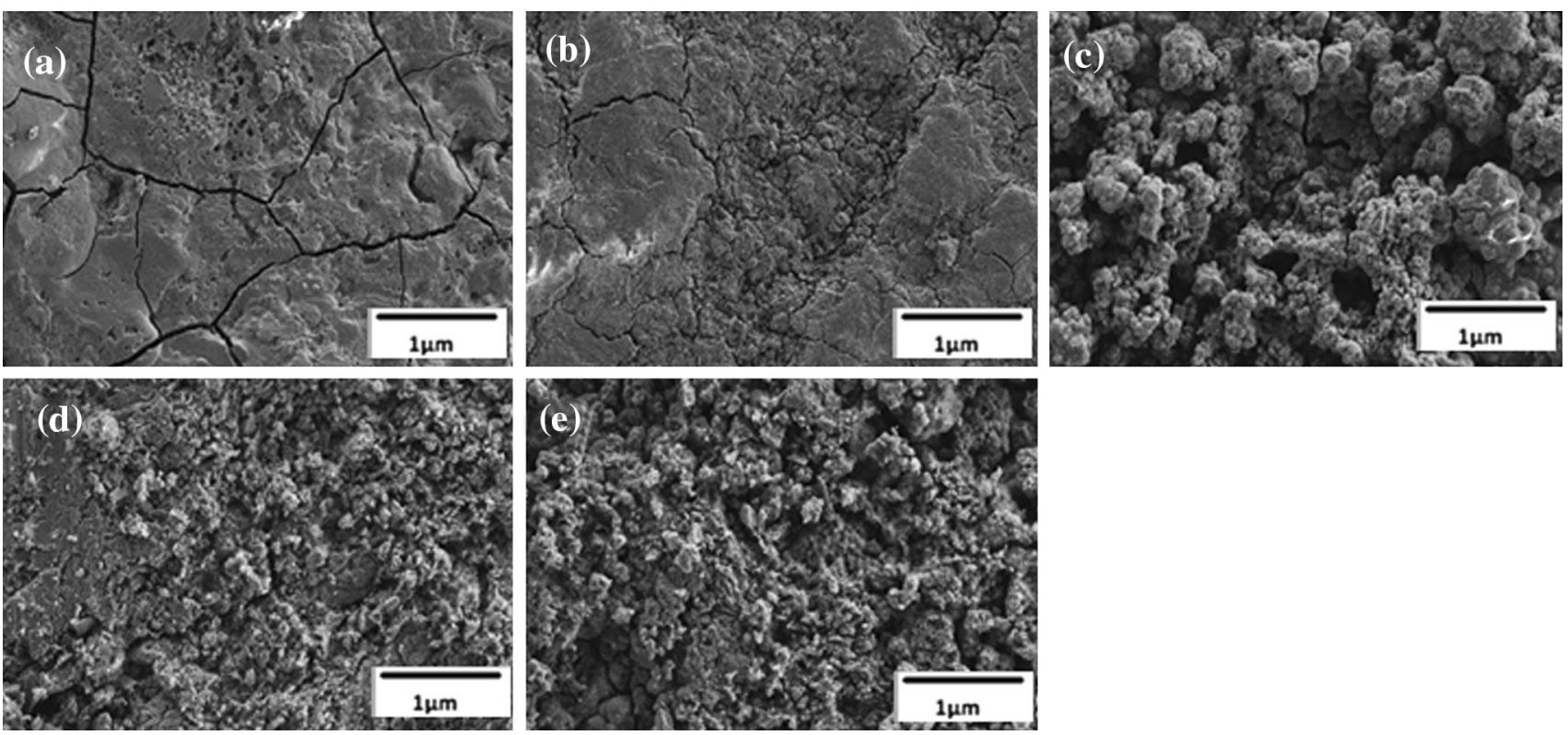

Fig. 9 Surface morphology after immersion in SBF for $5 \mathrm{~h}$ of the samples without HA a and with 1 wt $\%$ b, 5 wt $\%$ c, 8 wt $\%$ d and 11 wt $\%$ e HA
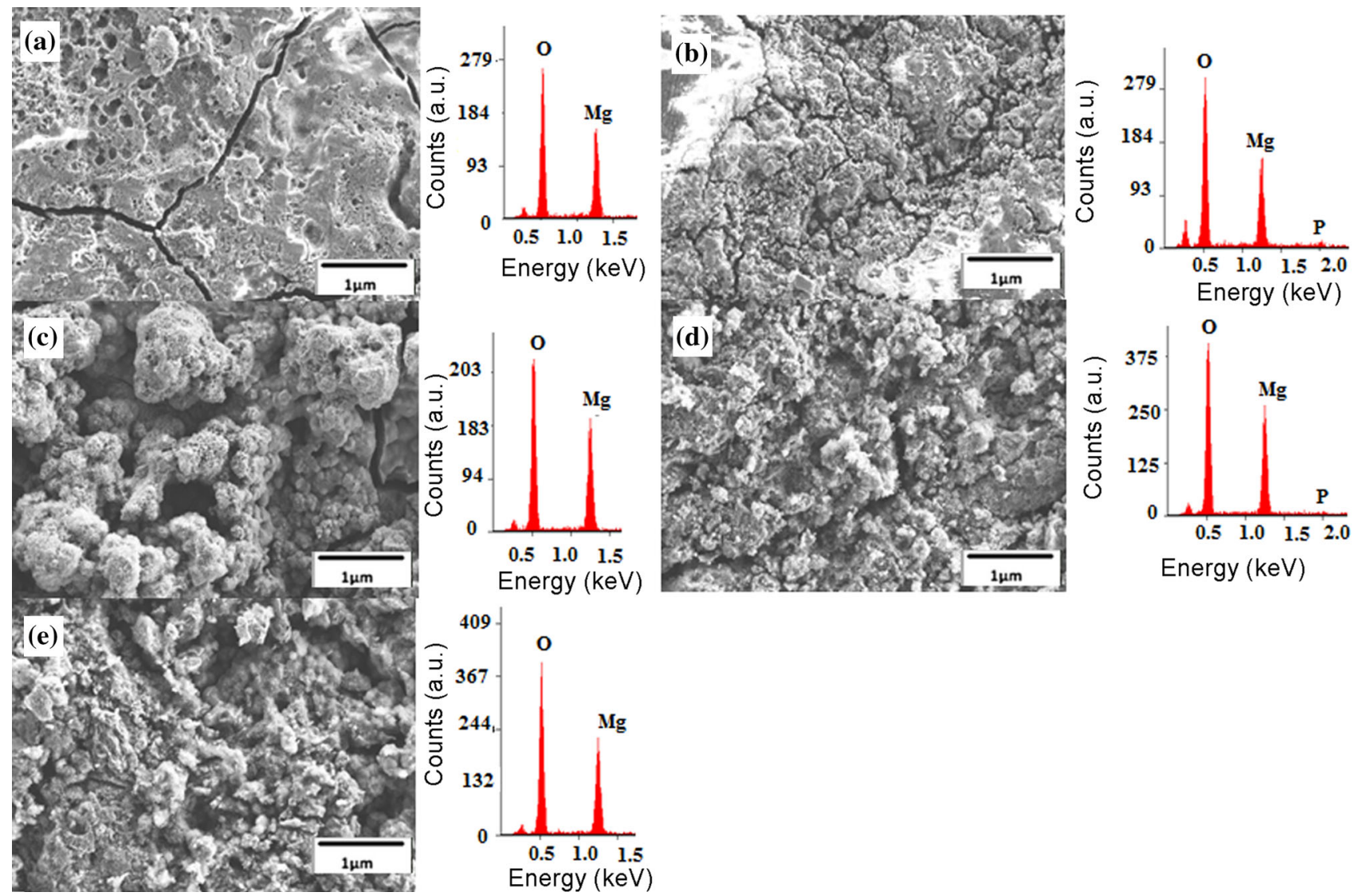

Fig. 10 EDX analysis of passivation layer on the samples with different HA contents: a 0 wt $\%$; b 1 wt $\%$; c 5 wt $\%$; d 8 wt $\%$; e 11 wt $\%$

content increased. Compressive strength of $\mathrm{Mg}-\mathrm{Zn} / \mathrm{HA}$ composite was a quadratic function of milling speed where the highest strength could be obtained when the speed was
$270 \mathrm{r} / \mathrm{min}$. A mathematical model equation for compressive strength of $\mathrm{Mg}-\mathrm{Zn} / \mathrm{HA}$ composite was developed. The prediction of compressive strength of $\mathrm{Mg}-\mathrm{Zn} / \mathrm{HA}$ composite 
based on the model equation was validated experimentally. The anomalous effect of BPR on the compressive strength observed in the present work shows that choice of BPR level need to be done carefully while designing the parameters for preparation of the composites. Results from immersion test indicated that corrosion resistance of $\mathrm{Mg}-$ $\mathrm{Zn} / \mathrm{HA}$ composite increases with HA content due to deposition of hydroxyapatite layer on the surface of $\mathrm{Mg}-$ $\mathrm{Zn} / \mathrm{HA}$ composite. Based on the results obtained from investigation on compressive strength and biodegradable properties of $\mathrm{Mg}-\mathrm{Zn} / \mathrm{HA}$ composite, addition of $8 \mathrm{wt} \%$ of HA is recommended because the compressive strength of sample with $8 \mathrm{wt} \% \mathrm{HA}$ is high and is within the range of bone's compressive strength (164-193 MPa).

Acknowledgments The authors would like to thank Ministry of High Education (FRGS Grant No. 6071304) for the financial support.

\section{References}

[1] S. Zhang, X. Zhang, C. Zhao, J. Li, Y. Song, C. Xie, H. Tao, Y. Zhang, Y. He, Y. Jiang, Acta Biomater. 6, 626 (2010)
[2] E.M. Salleh, H. Zuhailawati, S. Ramakrishnan, M. Gepreel, J. Alloys Compd. 644, 476 (2015)

[3] E. Zhang, D. Yin, L. Xu, L. Yang, K. Yang, Mater. Sci. Eng. C 29, 987 (2009)

[4] K. Khalil, E. Sherif, A. Almajid, Int. J. Electrochem. Sci. 6, 6184 (2011)

[5] D. Liu, M. Chen, X. Ye, Front. Mater. Sci. China 4, 139 (2010)

[6] Y. Zhao, J. Si, J. Song, X. Hui, Mater. Lett. 118, 55 (2014)

[7] M. Datta, D. Chou, D. Hong, P. Saha, S. Chung, B. Lee, A. Sirinterlikci, M. Ramanathan, A. Roy, P. Kumta, Mater. Sci. Eng. B 176, 1637 (2011)

[8] Q. Chang, H. Ru, D. Chen, X. Yue, L. Yu, C. Zhang, J. Mater. Sci. Technol. 27, 546 (2011)

[9] W. Cao, High Energy Ball Milling Process for Nanomaterial Synthesis. http://www.understandingnano.com/nanomaterial-synthesisball-milling.html. Accessed 6 Apr 2015

[10] K. Khalil, Int. J. Electrochem. Sci. 7, 10698 (2012)

[11] M. Hasniyati, H. Zuhailawati, S. Ramakrishnan, B. Dhindaw, S. Noor, Surf. Eng. 17, 432 (2015)

[12] F. Shehata, A. Fathy, M. Abdelhameed, S. Moustafa, Mater. Des. 30, 2756 (2009)

[13] H. Liebowitz, Fracture of Nonmetals and Composites (Academic Press, New York, 1972), pp. 780-782

[14] J. Howard, F. Allen, G. Shields, Implications of Molecular and Materials Structure for New Technologies Dordrecht (Springer, Netherlands, 1999)

[15] Z. Yang, J. Li, J. Zhang, G. Lorimer, J. Robson, Acta Metall. Sin. (Engl. Lett.) 21, 313 (2008) 